Open Access

\title{
Can formal innovation training improve group- and organizational-level innovativeness in a healthcare setting?
}

\author{
Joseph S. Schultz ${ }^{1 *}$, Endre Sjøvold ${ }^{2}$ and Beate André3,4
}

\author{
* Correspondence: \\ joseph.samuel.schultz@gmail.com \\ ${ }^{1}$ Faculty of Economics and \\ Management, Department of \\ Industrial Economics and \\ Technology Management, \\ Norwegian University of Science \\ and Technology, Trondheim, \\ Norway \\ Full list of author information is \\ available at the end of the article
}

\begin{abstract}
Purpose: Does formalization really destroy creative or innovative thinking? What if formal innovation training actually improved firm-level innovativeness? What if a manager could predict the likelihood of success or failure of such a program, prior to any resources being used? This is the aim of the study, to determine whether formalization has a positive impact on group- and organizational-level innovativeness. Additionally, this study will explore the extent to which success or failure of such a program can be predetermined, prior to the start of training.

Method: An intervention study was conducted in a healthcare setting. Quantitative and qualitative measurements were used in determining the effect of the formal innovation training. There were two groups: a participant group and a nonparticipant group. The intervention's express aim was to improve both group- and organizational-level innovativeness.
\end{abstract}

Findings: After the innovation intervention was completed, the participant group had a significant improvement in their understanding of innovation strategy and idea initiations, while the nonparticipant group had a significant improvement in innovation strategy. Additionally, eight innovative ideas emerged as a result of the training; three of those ideas were implemented and diffused within the organization.

Conclusion: First, this study showed that formalization could improve both group- and organizational-level innovativeness, which was contrary to theory. Second, this study indicated that the level of excitement and engagement in a group is essential to the success of this initiative. In this study, the participating group's level of excitement and engagement was so high that it seemed it was contagious to the rest of the organization. Even though the nonparticipant did not partake in any training, they learnt from it anyways, through the engagement of the participating group. Furthermore, the success of an innovation initiative can be predicted by looking to the innovative readiness of the group or organization.

Keywords: Cultural characteristics, Formalization, Innovative readiness, Innovation management, Process development 


\section{Background}

Innovation in healthcare is one of the most important developments for any modern society (Christensen, Grossman, \& Hwang, 2009), especially when considering the baby boomers that are approaching. It is known among healthcare practitioners that most developed countries will be experiencing unprecedented growths in their elderly population from 2020 to 2050 (Kulik, Ryan, Harper, \& George, 2014). However, what remains unclear is how these public organizations are going to meet these upcoming challenges. That is the aim of this study, to empirically test if formalization, by means of formal innovation training, will better prepare public organizations for the challenges to come. This aim will be tested by conducting an innovation intervention at a municipality that provides health care services for the elderly in their region. This study will measure the innovativeness between two groups within the same organization. One group will be participating in the innovation training, while the other group will be continuing work as usual or maintaining status quo. Each group's innovativeness will be measured, both before and after the innovation training is completed, to determine if the innovation intervention had an impact on either group's innovative capabilities.

The study makes an important contribution to innovation literature by testing a research question that has been posed and recommended for future research but has yet to be tested. A comprehensive review of innovation literature has failed to locate a single adequately conducted and reported intervention study (Anderson, Protocnik, \& Zhou, 2014, pp. 1321). There is a need for a "fully functional, pre- and postmeasurement designs, preferably with the use of participant and control group designs in real life organizational interventions with the express aim of improving individual-, group-, or organizational-level innovativeness" (Anderson et al., 2014, pp. 1321; see also Pierce \& Delbecq, 1977).

\section{Literature review}

\section{The need for innovation in eldercare}

Globally, the elderly population is expected to more than double, from 841 million people in 2013 to over 2 billion in 2050 (Nations, 2013). Most developed countries, like the USA, the UK, Australia, Japan, and Korea, are expecting their elderly population to double from 2013 to 2050 (Aging, 2014; Kulik et al., 2014). Norway is no different. From 2010 to 2050, their elderly population is expected to double (Statistics-Norway, 2012, 2014); the workforce is expected to decrease by $5 \%$ (Statistics-Norway, 2012), and municipalities have always struggled with filling enough municipal nursing vacancies due to poor perceptions of their working environment (Mæle 2014a, 2014b; Nordberg, 2013; Schultz, André, \& Sjøvold, 2016; Sundberg \& Samdal, 2013; Ulstein, 2006). The working environment for municipal nurses in Norway can be characterized by high stress, high absenteeism, little interest from newly educated nurses, high turnover, few educated nurses, and little emphasis on formal innovation training (Schultz, Sjøvold, \& André, 2017). In general, Norwegian municipalities providing eldercare are or will be experiencing many infrastructural challenges. As a result, this study has located one Norwegian municipal manager who decided that the time to think new or differently about how to deliver eldercare services is now. Prior research in the Norwegian eldercare sector has revealed that municipalities have had a clear strategy of improving the 
quality of care for the elderly using smart in-home technologies, but there has been little to no consideration given to the working environment (Schultz et al., 2016). Municipalities have acknowledged the need to think new or differently about the way they deliver healthcare services for their elderly but have yet to provide their employees with training on how to think innovatively (Schultz et al., 2016). This was the manager's wish, to build a culture or infrastructure for innovation within their department. This study hopes to fill that knowledge gap by providing formal innovation training.

Even though the municipality in this study agreed to participate in the formal innovation training, it is necessary to mention the inherent tension both in literature and in practice, between formalization and innovation. The tension stems from the belief that formal procedures create rigidity or unnecessary processes within an organization, and these additional loop innovators must jump through actually inhibit innovators from coming forward with their ideas (Pierce \& Delbecq, 1977; Thompson, 1965). As a result, many managers have chosen more open, free, autonomous, and undefined processes for innovation. This belief is far from uncommon. There is a body of organizational literature supporting this line of thought that "[R]outine activities are not likely to induce creative problem solving for those who are directed by formalized role prescriptions... [L]ow formalization permits openness in the system and that this openness is a necessary precondition for idea initiation" (Pierce \& Delbecq, 1977, pp. 31; see also Hage \& Aiken, 1967; Knight, 1967; Shepard, 1967). But what if it was proven that formalization, by means of innovation training, could improve group- and organizational-level innovativeness? Additionally, what if the success of that innovation training could be predicted, prior to the start, merely by looking to the innovative readiness of the participants? Would formalization then be such a bad thing? This study will attempt to challenge the traditional assumption that formalization hinders innovation.

\section{Formalization and its effects}

Formalization is a form of bureaucratic control, which "refers to the degree to which a codified body of rules, procedures, or behavior prescriptions is developed to handle decisions and work processing" (Pierce \& Delbecq, 1977, pp. 31). A common belief about formalization is that with more formalization comes more bureaucracy (Pierce \& Delbecq, 1977; Thompson, 1965). The more bureaucracy, the less motivated innovators will be in coming forward with their ideas (Pierce \& Delbecq, 1977; Thompson, 1965). This negative association between formalization and innovation has been around for more than half of a century (Thompson, 1965). Later empirical evidence has affirmed Thompson's findings that flexibility and low emphasis on work rules facilitate innovation (Hage \& Aiken, 1967; Kaluzny, Veney, \& Gentry, 1974) and low formalization permits openness, which encourages new ideas and behaviors (Knight, 1967; Pierce \& Delbecq, 1977; Shepard, 1967). A comprehensive review of innovation processes suggested that the relationship between innovation and formalization is best explained in terms of Thompson's innovation process:

(a) Initiation of an idea or proposal that when adopted and implemented will lead to the enactment of some change within the organization

(b)Adoption of the idea or proposal represents a decision being made by the organization's appropriate decision-maker(s) providing mandate and resources for the change 
(c) Implementation, the installation of the adopted idea into a sustained recognizable behavior pattern within the organization (Pierce \& Delbecq, 1977, pp. 29; see also Thompson, 1965; Zaltman, Duncan, \& Holbek, 1973, pp. 155)

The authors formulated a series of propositions, relating formalization to each stage of the innovation process: "Formalization will be negatively related to initiations, but will have a modest positive relationship to adoption and implementation" (Pierce \& Delbecq, 1977, pp. 31).

However, these suggested propositions representing the relationship between innovation and formalization have their shortfalls. The termed phases have become too traditional. Understanding and applying these terms given modern developments in literature has become difficult. These traditional terms do not distinguish clearly between the selection and development phases of an idea; they merely speak to the selection or financial support from the organization. Since 1977, organizational and innovation literature has grown in both the development (Christensen \& Raynor, 2003) and selection phases (Alexiev, Jansen, Van den Bosch, \& Volberda, 2010; Smith \& Tushman, 2005; West \& Anderson, 1996), which has made distinguishing and measuring accurately between these phases all the more important. Hansen and Birkinshaw (2007) have developed the innovation value chain, a modernized conceptualization of Thompson's innovation process. The innovation value chain measures innovation in three phases: idea generation (replaces initiations), idea conversion (replaces adoption/diffusion), and idea diffusion (replaces adoption/implementation). Hansen and Birkinshaw (2007, pp. 3) further explain their modernization of the innovation process:

The first of the three phases in the chain is to generate ideas; this can happen inside a unit, across units in a company, or outside the firm. The second phase is to convert ideas or, more specifically, select ideas for funding and developing them into products or practices. The third is to diffuse those products and practices.

Pierce and Delbecq (1977) suggested that the relationship between innovation and formalization is best explained in terms of Thompson's innovation processes. However, Hansen and Birkinshaw's (2007) conceptualization more clearly distinguishes between the development, selection, and diffusion phases. This modernization allows for a more accurate use and measurement of formal innovation processes, given modern developments in the literature. Additionally, their definition uses more modern termed phases, making the application of each phase in the process more intuitive. Unfortunately, there are apparent shortfalls with this model as well. There is a degree of ambiguity in determining where particular organizational or innovation literature should fit in the innovation value chain. For example, if an organization has difficulties in generating good ideas, creativity literature may shed light onto this, which would fit well within the idea generation phase (McAdam \& McClelland, 2002). However, what if the issue is more systemic, and a change is needed throughout the entire organization? In this case, organizational culture (Christensen, 2000; Edmondson, 1999; Harrison \& Carroll, 1991; Sørensen, 2002), organizational identity (Hannan \& Freeman, 1984; Oliver, 1991), or strategic direction in specific industries (Schultz, André, \& Sjøvold, 2015) may shed light onto the issue. If the issue is more systemic, it becomes more difficult to 
determine where those theories or strategies should fit within Hansen and Birkenshaw's model (e.g., organizational culture or organizational identity).

Accordingly, a hybrid model has been adopted. The hybrid model combines the two aforementioned phases (Hansen \& Birkinshaw, 2007; Thompson, 1965; Van de Ven, 2007). The main modification to the Hansen and Birkinshaw's model is the addition of one phase, innovation strategy. The addition of innovation strategy properly addresses issues that are more systemic to the organization. For example, if a manager wants to investigate the impact their organizational culture, identity, or strategic decisionmaking has on the firm's innovativeness. The addition of innovation strategy will accommodate for that.

These previous studies have described the relationships between innovation processes and formalization in depth, and they have made predictions about these relationships; however, these predictions have remained untested (Pierce \& Delbecq, 1977; Thompson, 1965). The gap this study is going to fill is testing whether formal innovation processes, by means of an innovation intervention, can actually improve group-level and, possibly, organizational-level innovativeness. This construct will test whether formalization is positively related to innovation as first prescribed by Pierce and Delbecq (1977), but the name of the phases are modified due to the modernization of the terms.

Hypothesis (H) 1: Formalization is positively related to innovation strategy (previously not a classification).

$\mathrm{H} 2$ : Formalization is positively related to idea generation (previously called initiations).

H3: Formalization is positively related to conversion (previously called adoptions but did not distinguish between selection and development clearly).

H4: Formalization is positively related to diffusion (previous classification unclear but likely implementation).

\section{Innovation and its effects}

Hansen and Birkenshaw's (2007) previously developed questionnaire will aid in measuring the intervention's participants' perceived impact that the formal innovation training has on the four defined stages. In addition to measuring the impact that formalization has on the different stages of the innovation process, this study would benefit by having a more objective measure of innovativeness, a measure more free from employee selfefficacy. For this reason, qualitative data will be gathered from management to measure more objectively if an innovation occurred per se. However, in order to determine if an innovation actually occurred, innovation first needs to be defined.

There is much ambiguity surrounding innovation; this definition varies dramatically depending on the context (Garcia \& Calantone, 2002; Johannessen, Olsen, \& Lumpkin, 2001; Ruvio, Shoham, Vigoda-Gadot, \& Schwabsky, 2014). This study is not searching for harmony between the various definitions, nor is it distinguishing between innovation and innovativeness (Ruvio et al., 2014), rather, this study has adopted a well-recognized definition of innovation. Innovation is the development and implementation of new ideas within the organization (Van de Ven, 1986; Daft, 1982; Damanpour, 1991; Damanpour \& Evan, 1984). If other forms of innovation are used, for example, innovativeness or innovative, they are being used in their literal, grammatical sense. 
Development refers to the generation of new ideas, while implementation refers to the diffusion of the new idea within the organization (Johannessen et al., 2001; Van de Ven, 1986), rather than focusing on commercial success or diffusion into the marketplace (Garcia \& Calantone, 2002). This part of the construct will measure whether formalization will lead to innovation(s), irrespective of improvements in innovation processes. Even though the formalization measures may show improvements in particular phases of the innovation process (or innovation potential), that does not necessarily mean the firm will be more innovative per se. To be innovative per se, the firm will have needed to develop a new idea(s) and implement and diffuse that idea within (or outside) the organization. This will be measured by gathering qualitative data from management.

H5: Formalization will be positively related to innovativeness.

\section{Innovative readiness for change}

Predetermining the success of any organizational initiative, prior to its implementation, is no easy task. Organizational readiness is one body of literature that seems to explore this issue. Organizational readiness refers to how an organization attempts to influence the beliefs, attitudes, intentions, and behavior of their organizational members (Armenakis \& Bedeian, 1999; Armenakis, Harris, \& Mossholder, 1993; Walker, Armenakis, \& Bernerth, 2007; Weiner, 2009; Weiner, Amick, \& Lee, 2008). At the core of readiness is the two-part message for change: (a) the need for change, which explains the discrepancy between the current state and the desired end-state, and (b) the individual and collective efficacy (or perceived ability to change) of the parties affected by the change (Armenakis et al., 1993). This concept was further operationalized by using group climate to explain part (b) of the two-part message for change test (Caliskan \& Isik, 2016; Eby, Adams, Russell, \& Gaby, 2000; Ingersoll, Kirsch, Merk, \& Lightfoot, 2000; Jones, Jimmieson, \& Griffiths, 2005). Subsequent research proposed that in theory, managers could predetermine the likelihood of success of an innovation initiative merely by looking to group climate, which should describe the group's innovative readiness for change (Schultz et al., 2017). Specifically, for one intervention study, it was hypothesized that the experimental group (those participating in formal innovation training) displayed group climate characteristics of innovative readiness for change, while the nonparticipant group (those that did not participate) did not (Schultz et al., 2017). To date, this theory has remained untested. This is an additional gap the study hopes to fill.

H6: Innovative readiness can be used as an indicator for predetermining the success of an innovative initiative?

\section{Results}

The results from this study, as illustrated in Table 1, show that both the participant group and nonparticipant group had statistical significance in innovation strategy (S1-S3). The participant group had significance for all the innovation strategy questions: S1 $(p<0.001), \mathrm{S} 2(p<0.05)$, and S3 $(p<0.01)$. The nonparticipant group also had significance for all the innovation strategy questions ( $1-\mathrm{S} 3(p<0.05))$.

The participant group had significance in four of seven idea generation questions (IG1-eIG2): IG1 $(p<0.01)$, IG2 $(p<0.05)$, IG3 $(p<0.001)$, and IG5 $(p<0.01)$. Additionally, 


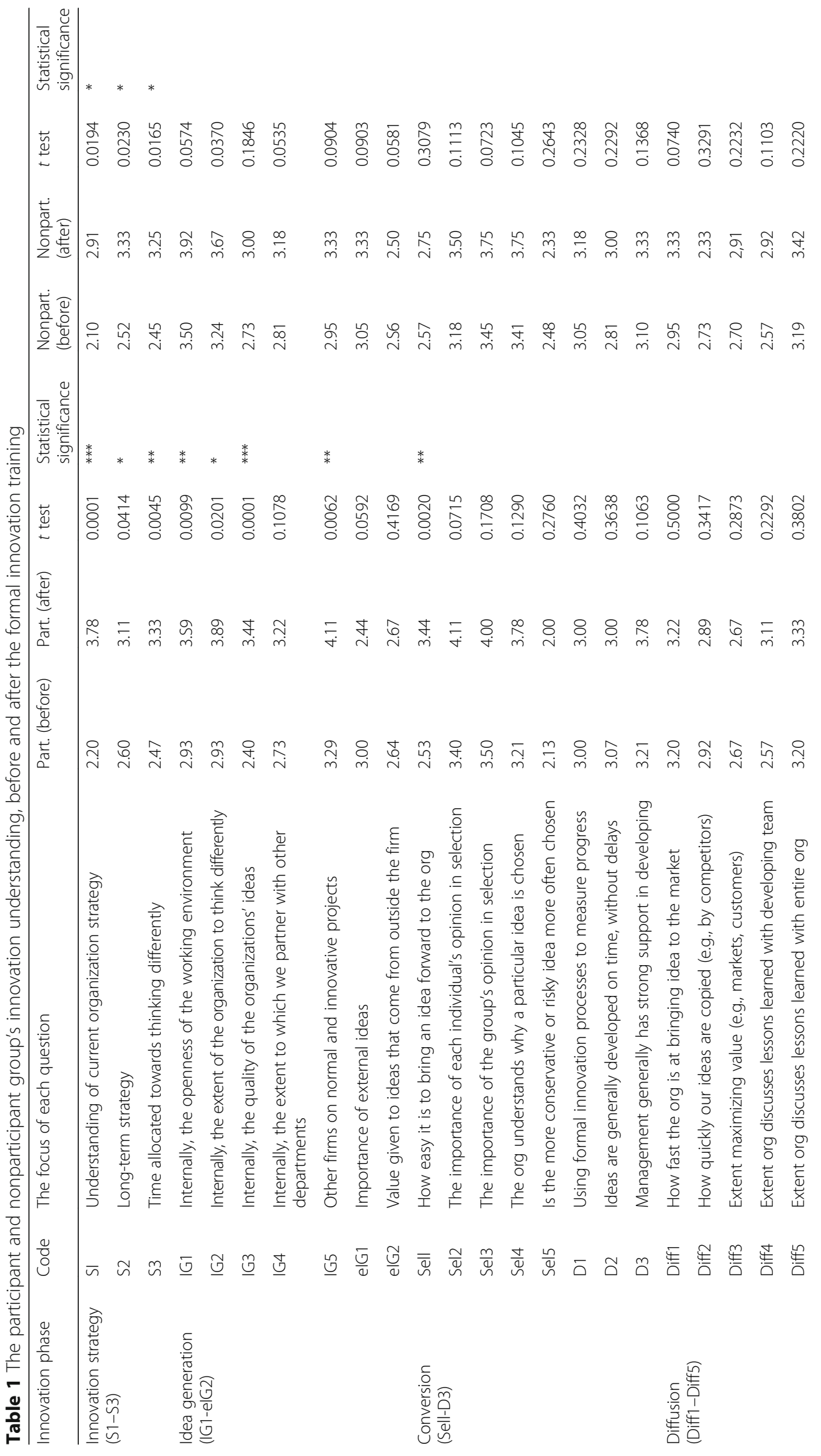




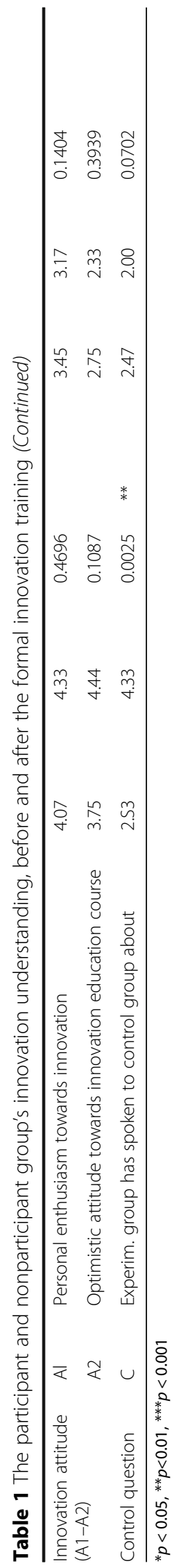


the participant group had significance for one conversion question (Sel1) $(p<0.01)$ and the control question $(C)(p<0.01)$.

Table 2 lists the innovative ideas that emerged as a result of the formal innovation training, and the extent to which each innovative idea was implemented within the Norwegian municipality. Eight ideas emerged from the innovation training; all ideas were discussed, seven ideas were selected and/or were being further developed (ideas 1-3 and 5-8), and three ideas were implemented and diffused within the organization (ideas 2, 5, and 7).

\section{Discussion}

This study has explored the relationship between formalization and innovation, the impact group dynamics can have on the organization, and the prediction of the success of formalization initiatives. The most significant finding was that formalization improves both group- and organizational-level innovativeness, which is contrary to theory. Additionally, we found that if the group participating in the formalization has a dominant group characteristic of excitement and engagement, this characteristic was contagious to the rest of the organization's nonparticipants. The results are summarized in Table 3.

First, formalization has a positive effect on group-level innovativeness. Prior to any innovation training, both the participant group and nonparticipant group had a relatively similar understanding of innovation (Schultz et al., 2017). This meant that neither group had statistical significance or advantage in their understanding of innovation prior to any training. However, after the participant group completed their formal training on innovation strategy, both the participant group and the nonparticipant group improved their understanding of innovation strategy significantly, thus supporting $\mathrm{H} 1$ (Table 3).

At first glance, the positive relationship between formal innovation training and improved understanding of innovation strategy for the participating group may not be that surprising. It seems logical that those who are interested and willingly chose to participate in innovation training will likely learn from it. Even if this is true that the participant group was biased prior to the training, the results still show that innovation

Table 2 Innovation ideas that derived from the formal innovation training

\begin{tabular}{|c|c|c|}
\hline Idea & Description of the idea & Extent implemented \\
\hline 1 & $\begin{array}{l}\text { Smaller units for elderly with dementia (with shielding protection needs) — units } \\
\text { sue too large now }\end{array}$ & $\mathrm{b}$ \\
\hline 2 & Changes in planning daily routines and tasks between day- and nighttime nurses & c \\
\hline 3 & $\begin{array}{l}\text { Have open dinner hours for } 1-2 \mathrm{~h} \text { to improve patients' appetite and to have less } \\
\text { chaos in the dining room }\end{array}$ & $b$ \\
\hline 4 & $\begin{array}{l}\text { Facilitate the receipt of patients with different backgrounds, today we are not } \\
\text { prepared for more }\end{array}$ & a \\
\hline 5 & Better estimates of food needs, waste less food & $c$ \\
\hline 6 & A more active use of PPS & $b$ \\
\hline 7 & Patient summary or overview completed in advance & c \\
\hline 8 & Improve interdisciplinary (across department) collaboration & b \\
\hline
\end{tabular}


Table 3 An overview of the tested hypotheses

\begin{tabular}{|c|c|c|}
\hline Hypotheses & & Status \\
\hline $\mathrm{H} 1$ & Formalization is positively related to innovation strategy & Supported \\
\hline $\mathrm{H} 2$ & Formalization is positively related to idea generation & $\begin{array}{l}\text { Supported, } \\
\text { in part }\end{array}$ \\
\hline H3 & Formalization is positively related to conversion & Inconclusive \\
\hline $\mathrm{H} 4$ & Formalization is positively related to diffusion & Inconclusive \\
\hline H5 & Formalization is positively related to innovativeness & Supported \\
\hline H6 & $\begin{array}{l}\text { Innovative readiness can be used as an indicator for } \\
\text { predetermining the success of an innovative initiative }\end{array}$ & Supported \\
\hline
\end{tabular}

(strategy) can be taught using formal training. This is an important finding as prior research has argued for 50 years that flexibility and low emphasis on work rules facilitate innovation (Hage \& Aiken, 1967; Kaluzny et al., 1974), and low formalization permits openness, which encourages new ideas and behaviors (Knight, 1967; Pierce \& Delbecq, 1977; Shepard, 1967). Contrary to the formalization theory, the statistical significance in Table 1 and results in Table 2 show that the (high) formalization, in the form of innovation training, has facilitated innovation for the participant group. The formal training has improved their understanding of both innovation strategy and idea generation (Table 1), and that improvement in innovation understanding has led to an emergence of eight new ideas (Table 2), three of which were implemented and diffused within the organization. This supported $\mathrm{H} 1$ and $\mathrm{H} 2$ for the participant group (Table 3).

Are there alternative explanations for this significance? What if the participating group merely believed they were more innovative because they participated in innovation training? Could that account for their significance? Table 1 dismisses these claims. If that were the case that the participating group believed they were more innovative after having completed the course, they would have had similar statistical significance in all or many of the innovation phases. However, they did not. Neither group could identify which questions on the survey were related to which innovation phases. After the training was completed, the participating group was statistically significant in only two of the four phases: innovation strategy (the phase they were given training in) and idea generation $(p<0.001)$. The significance in idea generation can be explained by looking to the nature of the courses. Innovation strategy can be tied closely with idea generation phase depending on which theories were discussed. There are some innovation strategy theories that could influence and overlap with idea generation.

Additionally, the study showed that the formal innovation training had a positive impact on the nonparticipant group's understanding of innovation strategy $(p<0.05)$, thus supporting H1, but not H2 (Table 3). This was odd. Members from this group were given the opportunity to join the innovation training, but they willingly chose not to participate. This group prioritized status quo or continuing business as usual, rather than participating in the training. Despite this lack of interest in the innovation training, their statistical significance in innovation strategy, illustrated in Table 1, indicated they learned from the training anyways. The nonparticipant group's significance was difficult to understand when looking solely to their group's data. However, when the nonparticipant group's data was viewed in light of the participating group's data and work climate, an explanation emerged. It seems the participating group's work climate 
as contagious to the nonparticipating group. The impact this had at the group level will be elaborated on below.

Second, formalization has a positive effect on organizational-level innovativeness. There were two indications that formalization affected the organizational-level innovativeness. First, Table 1 shows that the nonparticipant group has statistical significance $(p<0.05)$ in the innovation strategy phase, the same phase the participant group was taught. Here both groups, the participant and nonparticipant group, experienced statistical significance in the same phase. The combination of these two groups comprised the organization in this study. Meaning, learning reached the organizational level. This is fairly convincing evidence, as the nonparticipant group had no idea on which phase the participant group was participating in and could not determine which questions were associated with each phase on the questionnaire, and still, the nonparticipant group was only significant in one of the four phases on the questionnaire. If either group (the participant group or the nonparticipant group) really did not learn, and merely thought they were more innovative, more phases would have had significance. It is possible that this significance for both groups is a coincidence. However, when the evidence from Table 1 is viewed together with Table 2, the findings support the positive relationship for organizational-level innovativeness. Table 2 is an illustration of the qualitative data gathered from the management. Table 2 explains the ideas that emerged as a result of the formalization and the extent to which each idea was implemented within the organization. Table 2 shows that eight ideas emerged as a result of the training, seven ideas were further developed, and ideas 2, 5, and 7 were discussed, implemented, and diffused within the organization. Thus, formalization was positively related to organizational-level innovation as three new ideas were developed, implemented, and diffused within the organization, which supported H5 (Table 3).

Third, the results revealed that the group participating in the formalization had a dominant attitude of excitement and engagement towards the formalization; the evidence from this study suggests that this attitude was contagious to the rest of the organization's nonparticipants. Prior to any training, the participant group was clearly more enthusiastic about innovation than the nonparticipant group (Schultz et al., 2017). On average, each group member in the participant group was personally more enthusiastic and had a more optimistic attitude of the potential impact the formal innovation training course could have on their organization (Schultz et al., 2017). Thus, the participating group's work climate was clearly fostering an atmosphere of enthusiasm for innovation. Additionally, the participant group had a significant difference to the control question in Table 1. This question prompted the participant group to evaluate how often they spoke to the nonparticipant group about the innovation education that they received, and the participant group responded significantly $(p<0.01)$.

One possible explanation for the nonparticipant group's significance is that the participant group members contacted a number of nonparticipant group members and were able to educate them on innovation strategy. Participation in the formal innovation training was voluntary; the nonparticipant group members chose not to join. However, in the end, they learned anyways. It is difficult to understand how this learning came about, whether it was the nonparticipant group that eventually decided for themselves that they were ready to learn or whether the participant group had such a strong influence on the organization or nonparticipant group that they prevailed. 
Alternatively, the nonparticipant group members could have experienced a feeling of being "left out" and thus become competitive and tried to do well on the assessments. According to this study's measures, it seems most likely that the participant group's engagement or enthusiasm for innovation was contagious to the nonparticipant group. There is a body of organizational literature that supports the proposition that engagement is highly contagious and transferrable to other members of an organization (Barrick, Thurgood, Smith, \& Courtright, 2015; Pugh, 2001). However, this current study did not have these express measures in place to measure this issue accurately. For the aforementioned reasons, this phenomenon of an engaged or enthusiastic group influencing other nonparticipating members with their positive attitude to improve group or organizational innovativeness should be further explored.

Fourth, innovative readiness can be used to predict or predetermine if a group of participants are ready for innovative change. Prior to the intervention, both the participant group and nonparticipant group were classified in terms of their innovative readiness, based on their group climate (Schultz et al., 2017). It was determined that the participant group showed signs of innovative readiness for change, while the nonparticipant group did not (Schultz et al., 2017). This study confirmed this prediction for the participant group in Table 1 . Table 1 shows that the participating group significantly improved their understanding of innovation $(p<0.001)$ in the innovation phase they were taught, and this led to organization-wide innovations in Table 2. When Tables 1 and 2 are viewed together, they confirm that the participating group's innovative readiness was in fact a positive indicator of their successful participation in the innovation initiative. However, it was also predicted that the nonparticipating group was not ready for innovative change, but Table 1 presumably shows that this group did in fact change. This study did not have the appropriate measures in place to determine accurately how the nonparticipant group did in fact learn, even though they did not participate in any training. It seems plausible from Table 1 that the control question $(C)$ and the extent to which the participant group interacted with the nonparticipant group about what they learned from the intervention could have triggered this change for the nonparticipant group. If this were the case, it would not contradict the validity of innovative readiness. It would merely provide an explanation for an unexpected outcome. In this case, that one group's positive attitude was so strong that it convinced a group to be ready for innovation, even though they previously were not. Looking to group climate to predetermine innovative readiness for change was supported by $\mathrm{H} 6$ for the participant group, but H6 was inconclusive for nonparticipant group (Table 3).

Lastly, formalization focusing on one innovation phase can have a spillover effect to the other innovation phases. The relationship between "formalization and conversion" and "formalization and diffusion" was inconclusive as neither group received formalized training on either respective phase. Prior research identified innovation strategy as the weakest phase for this organization (Schultz et al., 2017). Accordingly, this organization received formal training only on innovation strategy. For this reason, the study's focus was on testing the impact that the formal training had on that phase of innovation. Even though the focus was on innovation strategy, all phases in the innovation process needed to be tested to account for possible spillover effects. This is one possible explanation for why the participant group had a significant improvement in their 
understanding of the idea generation phase. For these reasons, $\mathrm{H} 3$ and $\mathrm{H} 4$ were inconclusive (Table 3).

\section{Conclusions}

With the elderly population expected to nearly double in many developed countries from 2020-2050, health care practitioners have stated they must think new or differently about how they deliver their healthcare services, both in terms of technology they use and method they implore. This study has offered one proven method that will aid health practitioners in thinking new or differently about how they deliver their services. The most important outcome from this study showed that innovation or innovative thinking could actually be taught by means of formalization. Contrary to formalization theory, formal innovation training had a positive relationship to both group- and organizational-level innovativeness.

Additionally, this study showed the impact that a group of engaged or enthusiastic employees can have on the organization. The participant group in this study had a dominant group characteristic of interest in innovation. This study indicates that the participating group's excitement and engagement for innovation was likely contagious to the nonparticipating group. Even though the nonparticipant group chose to not participate in the formal training, in the end, they learned from it anyways by means of the participant group.

Furthermore, this study showed that managers could predetermine the likelihood of success of an innovative initiative merely by looking to group climate, which will shed light onto their innovative readiness for change.

The outcomes from this study have important implications to both theory and practice. Theoretically, the study provides quantitative and qualitative data in an area where data has previously been lacking (intervention studies developed specifically to improve both group- and organizational-level innovativeness) (Anderson et al., 2014; Pierce \& Delbecq, 1977; Schultz et al., 2016). Equally as important, the data from the study contradicts traditional formalization theory. Lastly, this study validates the determination of a group's innovative readiness by looking to their group climate. For managers, in the simplest terms, the study shows managers how they can start to think new or differently by implementing formal innovation training or a new innovation process within their organization. Interpreting the outcome one step further, the study could cause a shift on how organizations evaluate their workforce or hiring practices. This study shows that managers do not necessarily need to hire the most attractive or innovative employees available, rather, firms should try to first attempt to foster innovative growth from within the firm. Additionally, prior to putting time and money into a new innovation program, managers could now predetermine the likelihood of success of an innovative initiative merely by looking to their participating group's climate. These implications can have a significant impact on innovative development within organizations but also could shift hiring practices among firms attempting to become more innovative.

\section{Limitations}

The sample size is a limitation. There are not that many participants in this study $(N=40)$. Additionally, it may be a bit problematic to split the same department into two 
groups, one participating in the intervention and the other not, and have both evaluate their perception of the same organization's understanding of different phases of innovation. Ideally, there would have been two groups from two different organizations, one participating in the study and the other being the control group. However, this was not practically possible; this study only had access to one institution.

An additional limitation was the relationships that were tested. The only relationships that were tested were the improvement in innovation understanding between the participant and nonparticipants, both before and after formal training was completed. There should have been two more groups participating. One group should have been required to join, even though they did not want, to empirically test that impact. Another group, and perhaps the most interesting group that should have been included in the study, was a combination of both the participant group and the nonparticipant group. It would have been interesting to see the impact on both innovation understanding and group cultural dynamics if the nonparticipants' passiveness or negativity towards innovation would have been destructive for the participant members. Alternatively, maybe the participant members could convince the nonparticipants to be more active or engaged.

\section{Future research}

Innovation literature could benefit significantly by increasing the sample size, monitoring a longer duration, studying three groups (participant group, nonparticipant group, and a group combining participant and nonparticipant members), and expanding the study to different industries. This would likely shed more light unto the impact and transferability that formal innovation training has on both group- and organizationallevel innovativeness.

Additionally, the idea that innovation is contagious should further be explored. It was quite unexpected and surprising to think that the participating group's excitement and engagement for innovation was contagious to the nonparticipant group. This study was designed and structured more for measuring changes in group-level innovativeness, rather than the psychological factors influencing a nonparticipant group. It would be an interesting study to measure more precisely how the nonparticipant group learned what they did. There are many explanations: maybe the nonparticipant group merely learned how they wanted (from their colleagues) or that the participant group has so much influence over the organization that the nonparticipant group did not have a choice. Regardless, the finding was surprising and worth exploring further.

Lastly, innovative readiness needs to be further developed. It was accurate in predicting the success for the participating group, but the theory was inconclusive for the nonparticipating group, possibly due to the engagement from the participating group being contagious to the nonparticipant group. Before this theory can be validated, it needs to be further developed.

\section{Methods}

Mixed methods were used in conducting this formal innovation intervention (Brewer \& Hunter, 1989). Quantitative methods were used for gathering data relating to the relationship between formalization and innovation. The quantitative data was gathered twice; 
once prior to the innovation intervention and again after the intervention was completed. Lastly, qualitative data was gathered both from the ideas that surfaced during the workshop and from the management to more objectively determine if the formalization improved group- or organizational-level innovativeness.

\section{Study design}

After negotiations with management, it was determined that the municipality would allow 20 of their employees to participate in four, 2-h formal innovation training sessions. Management explained that this was all that was economically possible. If their employees are participating in the program, their wages need to be paid for that time; additionally, the municipality will need to find and pay for replacements for those shifts. The municipality solicited interest from their employees. For this reason, the study was broken into two groups: the participant group and the nonparticipant group. The participant group included those that volunteered to participate in the study, while the nonparticipant group included those employees that chose not to participate. It is important to note that the nonparticipant group is not a control group. The nonparticipant group did not know the content of the intervention, but they knew of the intervention's existence and willingly chose not to participate, thus shaping their attitudes prior to any measurements being taken. In actuality, we have two participant groups: one (the participant) group that chose to participate in the study and the other (the nonparticipant) group that chose not to participate. Prior to the intervention, both groups differed in their attitude towards the treatment. In this study, the organization as a whole is the combination of these two groups.

The participant group was exposed to four, 2-h formal training sessions. All four of the training sessions had a similar format. Each training session alternated between a lecture and group work approximately every $20 \mathrm{~min}$ throughout the 2-h session. Each small group was asked to apply the theories they learned from that day's lecture to different work-life scenarios. Each small group would come up with new ideas, based on that day's lecture (theory) and the task given to them. Each small group would then present their idea(s) to the others. After all the ideas were identified and discussed, the participant group as a whole would decide which idea(s) should be further developed.

The formalization of the training sessions lies in the structure (the process and measuring). First, prior to any innovation training, we identified the participants' level of innovation competence in four separate phases, based on a previously validated questionnaire (Hansen \& Birkinshaw, 2007). This provided the anchor or reference points for later measuring the impact that the four training sessions had on innovative outcomes. Second, we identified the weakest innovation phase, based on the participants' evaluation. The weakest phase for this group of participants was previously identified as the innovation strategy phase (Schultz et al., 2017). This will aid in determining which academic theories the participant group will benefit most from. Third, the formal innovation training conducted, incorporating the academic theories that should improve the previously identified, weakest phase (Table 4). Fourth, after the training was completed, the impact of the training was measured using the same questionnaire as mentioned in step 1. Fifth, the results from before and after the training were compared 
Table 4 Innovation theories related to each innovation phase

\begin{tabular}{|c|c|c|}
\hline Academic theory & Activity & Innovation phase \\
\hline $\begin{array}{l}\text { Introduction (mapping the journey), organizational } \\
\text { culture, organizational identity (organizational theory), } \\
\text { slack resources, stretch goals, absorptive capacity, } \\
\text { vicarious learning, disruptive innovation, transactional } \\
\text { cost theory, the end of competitive advantage. } \\
\text { Additional: eldercare theory, design thinking, blue } \\
\text { ocean strategy }\end{array}$ & Firm individual strategy & Innovation strategy \\
\hline $\begin{array}{l}\text { Open innovation, user-driven lead innovation, service } \\
\text { innovation (SDL), motivation (individual, group, and } \\
\text { organizational), psychological safety, slack resources, } \\
\text { team composition re-organizing the team, generating } \\
\text { movement in discussions, and network propinquity } \\
\text { (regional and relational) }\end{array}$ & $\begin{array}{l}\text { In-house idea generation; } \\
\text { In-house cross-pollination; } \\
\text { External sourcing of ideas }\end{array}$ & Idea generation \\
\hline $\begin{array}{l}\text { Ambidexterity (exploitation and exploration), impact of } \\
\text { management on innovation, and architectural modular } \\
\text { innovation. Additional: eldercare theory }\end{array}$ & Selection \& development & Conversion \\
\hline $\begin{array}{l}\text { Open innovation, organizational periphery, organizational } \\
\text { learning, network propinquity (regional and relational), } \\
\text { motivation (individual, groups, and organizations), and } \\
\text { roles of managers }\end{array}$ & Diffusion & Diffusion \\
\hline
\end{tabular}

using $t$ tests to identify significant changes. Sixth, gather qualitative data from management to more objectively determine if an innovation has occurred. Lastly, repeat the aforementioned steps as frequently as desired or needed; there should always be a phase in the process that can be improved. This structure needs to be strictly adhered to or this formalization will not have occurred properly.

Table 4 was originally developed in conjunction with the innovation value chain (Hansen \& Birkinshaw, 2007, pp. 6). However, for the aforementioned reasons, the authors have amended the table so that it includes the newly added phase (innovation strategy) and the additional applicable academic theories. In Table 4, innovation and organizational theories were classified into one of the four innovation phases. The inclusion of the academic theories developed over time. Originally, the academic theories included in Table 4 were based on $\mathrm{PhD}$ courses that had innovation strategy and innovation management at the core. Additional theories were added if they were industry-specific, emerging, and relevant for this study. Thus, academic theories in Table 4 will vary and evolve over time due to different environments and industries. Theories can be added, omitted, or repeated in each of the phases, but a competent researcher in the field of innovation or organizational literature should do this carefully.

This study, in effect, has two measures explaining the relationship between formalization and innovation. Hansen and Birkinshaw's modified questionnaire quantitatively measures the impact that formalization had on each of the four phases in the innovation process based on the participants' perception of their organization. Hansen and Birkinshaw's questionnaire does not determine if an innovation actually occurred, rather, it explains the extent to which phases within the innovation process have been improved (or innovation potential). The qualitative interview attempted to measure innovation more objectively and concretely. The review with management did not measure improvements in each innovation phase; it merely measured the result, whether an innovation per se occurred. 


\section{Quantitative data}

It can be difficult to quantitatively measure an organization's innovative culture, values, beliefs, or capabilities, as these concepts tend to be abstract or intangible in nature (Christensen, 2000; Gershon, Stone, Bakken, \& Larson, 2004; O’Reilly \& Tushman, 2004). It has been suggested that it is simpler to quantitatively measure innovative climate, rather than culture (Gershon et al., 2004). Innovative climate refers to the employees' perception or attitude of their organizations culture (Gershon et al., 2004). Accordingly, this study gathered quantitative data based on a previously developed questionnaire (Hansen \& Birkinshaw, 2007) that measured the participants' perception of their organizations' innovative culture. The original questionnaire was modified due to the shortfalls mentioned in the theoretical section above. This resulted in the questionnaire containing 25-items, rather than the original 13-items. Additionally, the scale was widened, from a 3-point to a 5-point Likert scale. Likert scales can range from a 2-point to a 10-point scale (Preston \& Colman, 2000). There has been a growing trend to scale up when using Likert scales (Preston \& Colman, 2000). However, a 10-point scale has been shown to produce slightly lower scores in general as compared with 5to 7-point scales (Preston \& Colman, 2000). This can mean that 10-point scales have too much variability for the respondent. For these reasons, this study chose to use a 5 -point Likert scale. The last modification was made to the style in which the question was prompted. Originally, the questions were prompted in the negative form. For example, "Your firm does not assign value to ideas that come from outside the firm ( $1=$ disagree and 3 =agree). Many of these questions were difficult to understand, especially when the question was asked in the negative, and the first evaluation response was in the negative $(1$ = disagree). There is a prevailing conventional wisdom that a mixture of positively and negatively worded items can counteract acquiescence response bias in surveys (Schriesheim \& Hill, 1981). However, empirical evidence shows that negatively worded items may not be an appropriate control for acquiescence response bias (Schriesheim \& Hill, 1981). Furthermore, negatively worded questions have been shown to impair response accuracy or, in other words, lead to respondent confusion (Schriesheim \& Hill, 1981). Consequently, the survey questions in this study were restructured so that they were posed in the positive form. The questionnaire measured the participants' individual perception of their organization's innovation competence in four different phases of innovation: innovation strategy, idea generation, conversion, and diffusion. The participants were unaware of these classifications or phases; however, our guide measured which questions corresponded with each innovation phase. The participants evaluated whether they strongly disagree (1), or strongly agree (5), with each posited innovation question. The data was collected twice; once prior to any formal training and, again, after the training was completed. The first questionnaire was given to both groups to determine which phase was evaluated as the weakest. The weakest phase was identified as innovation strategy (Schultz et al., 2017). The thought is that if an organization formalizes their innovation process, they will know which phase of the innovation needs the most improvement. After the weakest phase was identified (from the first questionnaire), the participant group received four, 2 -h formal innovation training sessions on that phase. The attendance was taken at the beginning of each session. The second questionnaire was then administered to both groups after the formal training was completed to determine if the training had 
any impact on either group or the organization as a whole. The questionnaire was administered in-person during the workshop for the participating group, while the questionnaire was sent electronically from the manager for the nonparticipating group. After the nonparticipating group's questionnaires were received, the data from the first and second questionnaires were compared to better understand the relationship that formalization had on the innovation process, both before and after the formalization.

This study compared each group's correlation significance (Cohen, Cohen, West, \& Aiken, 2013). Prior to any formal innovation training, both groups (the participant and nonparticipant group) completed the questionnaire to determine each group's initial level of innovation understanding. It is suggested that a $t$ test is an appropriate measure when distinguishing between two groups' innovative climate or perception of their innovative activity (André, Ringdal, Skjong, Rannestad, \& Sjøvold, 2016). Accordingly, a $t$ test was conducted to determine if there was any significant difference between either groups' innovation understanding prior to any training. After the formal innovation training was completed for the participant group, both groups completed the questionnaire once again. From the data gathered after the formal training, two additional correlation analyses were conducted. A correlation of each group's responses, both before and after the training, was conducted to determine if the formal training had any effect on either group's innovative climate. As suggested, $t$ tests were conducted to test the correlation significance (Sjøvold, 2007). This tested how each group member in the participant group perceived their innovation understanding before and after the training. We conducted the same $t$ test for the nonparticipant group, but the nonparticipant group never received any formal training; thus, it was expected that their responses for both the first and second questionnaire should remain relatively similar. This type of study, using a 5-point Likert scale to capture differences between two groups' innovative climate, using a $t$ test as the statistical analysis, has been previously validated (Schultz et al., 2017).

\section{Qualitative data}

Two different types of qualitative data were collected. First, data was collected from the ideas that surfaced during the training sessions. The training sessions consisted of both lectures and group work. During the lectures, the participants learned about various relevant academic theories (Table 4). During the group work, the participants applied the theory they were taught to work-life scenarios. It is recommended to have other researchers review the qualitative data that has been gathered in relation to research interpretations for quality assurance (Brinkman \& Kvale, 2015; Kvale, 1996). Obtaining other perspectives of the same qualitative data helps validate that the interpretations were accurate (Kvale, 1996). However, in this study, no interpretations were needed. Transcription of the group work was conducted with substantial attention given to preserving the meaning the participants gave to the ideas (Brinkman \& Kvale, 2015; Kvale, 1996). The ideas that surfaced from this group work, in all four training sessions, were the ideas that were transcribed (Table 2). The second form of qualitative data was gathered from an interview with management, after all the formal training was completed. Each idea in Table 2 was analyzed to determine the extent of its development. First, the 
management was asked if the idea was new and originated from this training session. Additionally, the management was asked to determine the extent of the idea's development in the organization: (1) only discussed; (2) discussed, selected, and developed in progress; and (3) discussed, selected, developed, implemented, and diffused within the organization. If an idea made it through step three, then an innovation occurred, and the formalization had a positive impact on innovation, irrespective of the participating group's self-efficacy. It was difficult to control for reliability and validity of this data (Brinkman \& Kvale, 2015; Kvale, 1996), as the information that was transcribed was based solely on the manager's knowledge.

\section{Subjects and data collection}

An innovation intervention was conducted. Data was collected from 40 health care practitioners $(N=40)$, from a publicly owned retirement home located in a rural part of Trøndelag, in Norway. The practitioners were divided into two groups, the participant group $(N=15)$ and the nonparticipant group $(N=25)$. The participant group will be participating in a formal innovation education, while the nonparticipant group will be conducting business as usual or maintaining status quo. Both groups are comprised of a unit leader, registered nurses, nursing assistants, and others. Participation in the formal innovation training was voluntary, meaning, the nonparticipant group members chose not to join.

Prior to any formal training, both groups completed the first questionnaire. From the participant group, 15 of 15 (100\%) responded to the questionnaire sufficiently. The response rate was likely so high as the questionnaire was completed at the start of the first innovation training course. From the nonparticipant group, 22 of 25 (88\%) were sufficiently completed. The response rate could have been lower because the questionnaire was sent electronically, from the manager to the employees, and the questionnaire was completed on their own time. At the conclusion of the innovation course, 10 of 15 (67\%) questionnaires were sufficiently completed from the participant group, while the nonparticipant group completed 12 of 25 (48\%) sufficiently. The second questionnaire for each group was completed in the same manner as the first questionnaire. The participant group completed their second questionnaire at the conclusion of the last innovation training course, while the nonparticipant group completed an electronic questionnaire on their own time.

Participation in this study was voluntary, and the participants could withdraw from the study at any point. The participants were informed about what their participation in the innovation training entailed and that their participation was going to be measured, and the results might be published as research. All data were registered anonymously to preserve the confidentiality of the participants. Management from both the unit and municipality approved the study. 


\section{Competing interests}

The authors declare that they have no competing interests.

\section{Publisher's Note}

Springer Nature remains neutral with regard to jurisdictional claims in published maps and institutional affiliations.

\section{Author details}

${ }^{1}$ Faculty of Economics and Management, Department of Industrial Economics and Technology Management, Norwegian University of Science and Technology, Trondheim, Norway. ${ }^{2}$ Faculty of Economics and Management, Department of Industrial Economics and Technology Management, Norwegian University of Science and Technology, Trondheim, Norway. ${ }^{3}$ Faculty of Medicine and Health Sciences, Department of Public Health and Nursing, Norwegian University of Science and Technology, Trondheim, Norway. ${ }^{4}$ NTNU Centre for Health Promotion Research, Trondheim, Norway.

Received: 23 December 2016 Accepted: 9 May 2017

Published online: 05 July 2017

\section{References}

Aging, A. o. (2014). Aging statistics. Department of Health and Human Services. Retrieved from http://www.aoa.gov/ Aging_Statistics/.

Alexiev, A. S., Jansen, J. J. P., Van den Bosch, F. A. J., \& Volberda, H. W. (2010). Top management team advice seeking and exploratory innovation: the moderating role of TMT heterogeneity. Journal of Management Studies, 47(7), 1343-1364.

Anderson, N., Protocnik, K., \& Zhou, J. (2014). Innovation and creativity in organizations: a state-of-the-science review, prospective commentary, and guiding framework. Journal of Management, 40(5), 1297-1333.

André, B., Ringdal, G. l., Skjong, R. J., Rannestad, R., \& Sjøvold, E. (2016). Exploring experiences of fostering positive work environment in Norwegian nursing homes: a multi method study. Clinical Nursing Studies, 4(4), 9-17.

Armenakis, A. A., \& Bedeian, A. G. (1999). Organizational change: a review of theory and research in the 1990s. Journal of Management, 25(3), 293-315

Armenakis, A. A., Harris, S. G., \& Mossholder, K. W. (1993). Creating readiness for organizational change. Human Relations, 46(6), 681-703.

Barrick, M. R., Thurgood, G. R., Smith, T. A., \& Courtright, S. H. (2015). Collective organizational engagement: linking motivational antecedents, strategic implementation, and firm performance. Academy of Management Journal, 58(1), $111-135$.

Brewer, J., \& Hunter, A. (1989). Multimethod research: a synthesis of styles (Vol. 175). Thousand Oaks, CA: Sage Publications, Inc

Brinkman, S., \& Kvale, S. (2015). Interviews: learning the craft of qualitative research interviewing. Thousand Oaks, CA: Sage Publications, Inc.

Caliskan, S., \& Isik, I. (2016). Are you ready for the global change? Multicultural personality and readiness for organizational change. Journal of Organizational Change Management, 29(3), 404-423.

Christensen, C. M. (2000). The innovator's dilemma: when new technologies cause great firms to fail. Boston, MA: Harvard Business School Publishing.

Christensen, C. M., Grossman, J. H., \& Hwang, J. (2009). The innovator's prescription: a disruptive solution for health care. New York, NY: McGraw Hill.

Christensen, C. M., \& Raynor, M. E. (2003). The innovator's solution: creating and sustaining successful growth. Boston, MA: Harvard Business School Publishing Corporation.

Cohen, J., Cohen, P., West, S. G., \& Aiken, L. S. (2003). Applied multiple regression/correlation analysis for the behavioral sciences. Mahwah: Lawrence Erlbaum Associates, Inc., Publishers.

Daft, R. L. (1982). Bureaucratic versus nonbureaucratic structure and the process of innovation and change (Vol. 1). Greenwich, CT: JAI Press.

Damanpour, F. (1991). Organizational innovation: a meta-analysis of effects of determinants and moderators. Academy of Management Journal, 34(3), 555-590

Damanpour, F., \& Evan, W. M. (1984). Organizational innovation and performance: the problem of "organizational lag". Administrative Science Quarterly, 29(3), 392-409.

Eby, L. T., Adams, D. M., Russell, J. E. A., \& Gaby, S. H. (2000). Perceptions of organizational readiness for change: factors related to employees' reactions to the implementation of team-based selling. Human Relations, 53(3), 419-442.

Edmondson, A. (1999). Psychological safety and learning behavior in work teams. Administrative Science Quarterly, 44(2), 350-383.

Garcia, R., \& Calantone, R. (2002). A critical look at technological innovation typology and innovativeness terminology: a literature review. The Journal of Product Innovation Management, 19(2), 110-132.

Gershon, R. R. M., Stone, P. W., Bakken, S., \& Larson, E. (2004). Measurement of organizational culture and climate in healthcare. The Journal of Nursing Administration, 34(1), 33-40.

Hage, J., \& Aiken, M. (1967). Program change and organizational properties: a comparative analysis. American Journal of Sociology, 72(5), 503-519.

Hannan, M. T., \& Freeman, J. (1984). Structural inertia and organizational change. American Sociological Review, 49(2), 149-164.

Hansen, M. T., \& Birkinshaw, J. (2007). The innovation value chain. Harv Bus Rev, 85, 1-13.

Harrison, J. R., \& Carroll, G. R. (1991). Keeping the faith: a model of cultural transmission in formal organizations. Administrative Science Quarterly, 36(4), 552-582.

Ingersoll, G. L., Kirsch, J. C., Merk, S. E., \& Lightfoot, J. (2000). Relationship of organizational culture and readiness for change to employee commitment to the organization. Journal of Nursing Administration, 30(1), 11-20. 
Johannessen, J., Olsen, B., \& Lumpkin, G. T. (2001). Innovation as newness: what is new, how new, and new to whom? European Journal of Innovation Management, 4(1), 20-31.

Jones, R. A., Jimmieson, N. L., \& Griffiths, A. (2005). The impact of organizational culture and reshaping capabilities on change implementation success: the mediating role of readiness for change. Journal of Management Studies, 42(2), 361-386.

Kaluzny, A. D., Veney, J. E., \& Gentry, J. T. (1974). Innovation of health services: a comparative study of hospitals and health departments. The Milbank Memorial Fund Quarterly, 52(1), 51-82.

Knight, K. E. (1967). A descriptive model of the intra-firm innovation process. The Journal of Business, 40(4), 478-496.

Kulik, C. T., Ryan, S., Harper, S., \& George, G. (2014). From the editors: aging populations and management. Academy of Management Journal, 57(4), 929-935. doi:10.5465/amj.2014.4004.

Kvale, S. (1996). InterViews: an introduction to qualitative research interviewing. Thousand Oaks, CA: SAGE Publications.

McAdam, R., \& McClelland, J. (2002). Individual and team-based idea generation within innovation management: organisational and research agendas. European Journal of Innovation Management, 5(2), 86-97.

Mæle, S. M. (2014a, 17.06.2014). No thank you to Trondheim municipality (Takker nei til Trondheim kommune). Høgskoleavisa.

Mæle, S. M. (2014b, 28.08.2014). Several municipalities do not have enough nurses (Flere kommuner har sykepleiermangel). Høgskoleavisa.

Nations, U. (2013). World population ageing 1950-2050. United Nations, Department of Economic and Social Affairs, Population Division. Retrieved from http://www.un.org/en/development/desa/population/publications/pdf/ageing/ WorldPopulationAgeing2013.pdf. Accessed 23 Dec 2016

Nordberg, M. S. (2013, 26.09.2013). Competence and eldercare (kompetanse og eldreomsorg). Adressa.

O'Reilly, C. A., \& Tushman, M. L. (2004). The ambidextrous organization. Harvard Business Review, 82(4), 74-81.

Oliver, C. (1991). Strategic responses to institutional processes. Academy of Management Review, 16(1), 145-179.

Pierce, J. L., \& Delbecq, A. L. (1977). Organization structure, individual attitudes and innovation. Academy of Management Review, 2(1), 27-37

Preston, C. C., \& Colman, A. M. (2000). Optimal number of response categories in rating scales: reliability, validity, discriminating power, and respondent preferences. Acta Psychologica, 104, 1-15.

Pugh, S. D. (2001). Service with a smile: emotional contagion in the service encounter. Academy of Management Journal, 44(5), 1018-1027.

Ruvio, A. A., Shoham, A., Vigoda-Gadot, E., \& Schwabsky, N. (2014). Organizational innovativeness: construct development and cross-cultural validation. The Journal of Product Innovation Management, 31(5), 1004-1022.

Schriesheim, C. A., \& Hill, K. D. (1981). Controlling acquiescence response bias by item reversals: the effect on questionnaire validity. Educational and Psychological Measurement, 41(4), 1101-1114.

Schultz, J. S., André, B., \& Sjøvold, E. (2015). Demystifying eldercare: managing and innovating from a public-entity's perspective. International Journal of Healthcare Management, 8(1), 42-57.

Schultz, J. S., André, B., \& Sjøvold, E. (2016). Managing innovation in eldercare: a glimpse into what and how public organizations are planning to deliver healthcare services for their future elderly. International Journal of Healthcare Management, 9(3), 169-180.

Schultz, J. S., Sjøvold, E., \& André, B. (2017). Can work climate explain innovative readiness for change? The Journal of Organizational Change Management, 30(3), 1-12. doi:10.1108/JOCM-06-2016-0112.

Shepard, H. A. (1967). Innovation-resisting and innovation-producing organizations. The Journal of Business, 40(4), 470-477.

Sjøvold, E. (2007). Systematizing Person-Group Relations (SPGR): a field theory of social interaction. Small Group Research, 38(5), 615-635.

Smith, W. K., \& Tushman, M. L. (2005). Managing strategic contradictions: a top management model for managing innovation streams. Organization Science, 16(5), 522-536.

Statistics-Norway. (2012). On the verge of coordination (På randen av samhandling) (2011/5-6). Retrieved from Oslo, Norway: http://www.ssb.no/folkemengde_en/arkiv/tab-2012-02-23-01-en.html. Accessed 23 Dec 2016.

Statistics-Norway. (2014). Population projections, 2014-2100. Retrieved from Oslo, Norway.

Sundberg, C. Ø., \& Samdal, M. (2013, 28.08.2013). One of four in the nursing homes have a college education (Kun en av fire i sykehjemmene har høyskoleutdanning). Adressa.

Sørensen, J. (2002). The strength of corporate culture and the reliability of firm performance. Administrative Science Quarterly, 47(1), 70-91.

Thompson, V. A. (1965). Bureaucracy and innovation. Administrative Science Quarterly, 10(1), 1-20.

Ulstein, K. (2006). Increased knowledge of elder care in the Nordic countries. The Research Council of Norway (Forskningsrådet). Retrieved from Oslo, Norway: http://www.forskningsradet.no/no/Nyheter/Hva vet_vi_om eldreomsorg_i Norden/ 1236685410951

Van de Ven, A. H. (1986). Central problems in the management of innovation. Management Science, 32(5), 560-607.

Van de Ven, A. H. (2007). Engaged scholarship: a guide for organizational and social research. New York, NY: Oxford University Press Inc

Walker, H. J., Armenakis, A. A., \& Bernerth, J. B. (2007). Factors influencing organizational change efforts: an integrative investigation of change content, context, process and individual differences. Journal of Organizational Change Management, 20(6), 761-773.

Weiner, B. J. (2009). A theory of organizational readiness for change. Implementation Science, 4(67), 1-9.

Weiner, B. J., Amick, H., \& Lee, S. D. (2008). Conceptualization and measurement of organizational readiness for change: a review of the literature in health services research and other fields. Medical Care Research and Review, 65(4), 379-436.

West, M. A., \& Anderson, N. R. (1996). Innovation in top management teams. Journal of Applied Psychology, 81(6), 680-693.

Zaltman, G., Duncan, R., \& Holbek, J. (1973). Innovation and organizations. New York: Wiley. 